\title{
A construção de Planos de Ensino Individualizados (PEIs) em um colégio de aplicação: trajetória e desafios
}

Camila Camilozzi Alves Costa de Albuquerque Araújo ${ }^{1}$ Maria Carolina da Silva Caldeira ${ }^{2}$ Ana Luísa Alves ${ }^{3}$

\begin{abstract}
Resumo:
Este artigo tem como objetivo analisar o processo de construção de Planos de Ensino Individualizados (PEIs) no Centro Pedagógico (CP/UFMG), colégio de aplicação que oferta o ensino fundamental em tempo integral, com reserva de vagas para estudantes público-alvo da educação especial (PAEE). 0 PEI é um documento para registrar o processo de inclusão de educandos que demandem adaptações curriculares, sejam eles estudantes PAEE ou não, bem como para traçar as metas específicas de aprendizagem, os avanços e as dificuldades vivenciadas no contexto inclusivo. Com base na perspectiva da educação inclusiva e nas contribuições de Tannús-Valadão; Mendes (2018) e Poker (2013), pretende-se mostrar como o processo de discussão desses Planos tem se dado no Colégio, no período de 2014 a 2021, evidenciando os modos como eles são ressignificados na instituição e os embates que envolvem a construção desse documento. Para isso, foram utilizadas três estratégias metodológicas: pesquisa bibliográfica, pesquisa documental e grupo focal. As análises indicam um processo constante na escola de reflexões a respeito do $\mathrm{PEI}$, bem como desafios quanto à construção de um modelo adequado às demandas da instituição. Mostram também a necessidade de consolidação do trabalho coletivo para a produção desse documento e sua efetivação na prática.
\end{abstract}

\section{Palavras-chave:}

Planejamento de ensino. Inclusão. Adaptação curricular. Plano de ensino individualizado.

\footnotetext{
1 Mestre em Administração Pública pela Fundação João Pinheiro. Pedagoga do Centro Pedagógico da Escola de Educação Básica e Profissional da UFMG. Membro do Núcleo de Estudos e Pesquisas sobre Educação Inclusiva e Diversidade - NEPED (NEPED/ CP/UFMG). E-mail: camila.camilozzi@gmail.com. ORCID iD: http://orcid.org/0000-0001-9804-5888.

2 Doutora e Mestre em Educação (UFMG). Professora do Centro Pedagógico da Escola de Educação Básica e Profissional da UFMG e do Programa de Pós-Graduação em Educação: Conhecimento e Inclusão Social. Membro do Núcleo de Estudos e Pesquisas sobre Educação Inclusiva e Diversidade - NEPED (NEPED/CP/UFMG). E-mail: mariacarolinasilva@hotmail.com. ORCID iD: http://orcid.org/0000-0003-0668-1989.

3 Estudante de Graduação em Matemática da Universidade Federal de Minas Gerais. Bolsista de Iniciação Científica do Neped. E-mail: analuisazxc@gmail.com. ORCID iD: http://orcid.org/0000-0002-8632-4190.
} 


\section{The construction of Individualized Education Program (IEPs) in an application school: trajectory and challenges}

\section{Abstract:}

This article aims to analyze the process of building Individualized Education Program (IEPs) in Pedagogical Center (CP/UFMG), an application school that offers full-time elementary education and reserves places for public students target of special education. The IEP is a document to register the process of inclusion of students who require curricular adaptations, whether they are special students or not, as well as to outline the specific learning goals, advances and difficulties experienced in the inclusive context. Based on the perspective of inclusive education and contributions of Tannús-Valadão; Mendes (2018); Poker (2013), it is intended to show how the process of discussing these Plans has taken place in the school from 2014 to 2021, highlighting the ways in which they are re-signified in the institution and the clashes that involve the construction of this document. For this, three methodological strategies were used: bibliographic research, documentary research and focus group. The analyzes indicate a constant process in the school of reflections about the IEP, as well as challenges regarding the construction of a model adequate to the demands of the institution. They also show the need to consolidate collective work for the production of this document and its effectiveness in practice.

\section{Keywords:}

Teaching planning. Inclusion. Curricular adaptation. Individualized Education Program.

\section{La construcción de Planes de Enseñanza Individualizados (PEI) en una escuela de aplicación: trayectoria y desafios}

\section{Resumen:}

Este artículo tiene como objetivo analizar el proceso de construcción de Planes de Enseñanza Individualizados (PEI) en Centro Pedagógico (CP/UFMG), una escuela de aplicación que ofrece educación primaria de tiempo completo, com lugares para estudiantes públicos-objetivo de educación especial (PAEE). EI PEI es un documento para registrar el proceso de inclusión de los estudiantes que requieren adaptaciones curriculares, sean o no estudiantes PAEE, y para delinear los objetivos de aprendizaje específicos, los avances y las dificultades vividas en el contexto inclusivo. Basado en la perspectiva de la educación inclusiva y contribuciones de Tannús-Valadão; Mendes (2018) e Poker (2013), se pretende mostrar cómo se ha desarrollado el proceso de discusión de estos Planes en CP desde 2014 hasta 2021, destacando las formas en que se resignifican en la institución y los conflictos que implican la construcción de este documento. Para ello se utilizaron tres estrategias metodológicas: investigación bibliográfica, investigación documental y focus group. Los análisis señalan un proceso en la escuela de reflexiones sobre el PEl, así como desafíos en la construcción de un modelo adecuado a las demandas de la institución. También muestran la necesidad de consolidar el trabajo colectivo para la producción de este documento y su efectividad.

Palabras clave:

Planificación docente. Inclusión. Adaptación curricular. Plan de enseñanza individualizado.

\section{Introdução}

O Plano de Ensino Individualizado (PEI) ou Plano de Desenvolvimento Individual (PDI) é compreendido aqui como um documento fundamental para registrar o processo de inclusão de educandos que demandem adaptações curriculares, sejam eles estudantes público-alvo da 
educação especial (PAEE) ${ }^{4}$ ou não, bem como para traçar as metas específicas de aprendizagem, os avanços e as dificuldades vivenciadas no contexto inclusivo. Dessa feita, este artigo tem como objetivo analisar o processo de construção de PEIs/PDIs no Centro Pedagógico da UFMG (CP/ UFMG), colégio de aplicação que oferta o ensino fundamental em tempo integral e que realiza reserva de vagas para estudantes público-alvo da educação especial (PAEE). Nesse sentido, pretende-se mostrar como o processo de discussão desses planos tem se dado no Colégio, no período de 2014 a 2021, evidenciando os modos como eles são ressignificados na instituição e os embates que envolvem a construção desse documento.

A ideia de construir um PEI/PDI parte do princípio de que o planejamento deve ser centrado no indivíduo (TANNÚS-VALADÃO; MENDES, 2018), ou seja, o educando tem direito a um planejamento que foque no seu desenvolvimento individual, aprofundando suas relações pessoais e seu processo de aprendizagem. O PEI/PDI insere-se, portanto, em um contexto que considera os estudantes como "seres únicos e singulares que se diferenciam e se multiplicam" (LIMA; MANTOAN, 2017, p. 831). Considerando-se esse aspecto, há consequências sobre os processos de ensino e de aprendizagem. Estes não podem ser realizados de forma homogênea para todos, sendo necessário, portanto, adaptar metas, recursos e metodologias visando à inclusão dos educandos.

O Centro Pedagógico, ao longo do processo de inclusão, tem construído e experimentado diferentes modelos de PEI/PDI a fim de pensar nas estratégias mais adequadas para cada educando. Esse processo de construção mostra alguns dos dilemas, dúvidas e conflitos que envolvem a inclusão desses estudantes. Nesse sentido, o estudo aqui apresentado justifica-se na medida em que permite compreender esse processo ao longo do tempo em uma escola, ao mesmo tempo em que contribui para o debate no campo de estudos da educação inclusiva, por mostrar diferentes modos de pensar o referido documento, tão importante no processo educacional de estudantes com demandas específicas de ensino-aprendizagem.

Para analisar esse processo, este artigo utiliza três estratégias metodológicas principais. A primeira delas é a pesquisa bibliográfica e consulta à literatura já publicada na área. A segunda refere-se à análise dos documentos disponíveis na escola a respeito dos Planos de Ensino Individualizados, na qual foram levantados diferentes documentos presentes na escola que registram o processo de construção de PEIs/PDIs, como atas, e-mails, excertos do Projeto Político-Pedagógico, entre outros. A terceira estratégia metodológica refere-se à análise de falas de docentes em grupos focais realizados em 2019 que discutiam sobre os desafios na construção de PEIs/PDIs. No caso aqui analisado, os grupos focais discutiram questões gerais relativas à inclusão.

Para demonstrar como o PEI/PDI tem sido utilizado na escola como importante ferramenta no processo inclusivo, este artigo divide-se em seis partes, sendo a primeira delas esta introdução. A segunda parte consiste na apresentação da metodologia adotada. Na terceira, apresenta-se um breve histórico sobre como a discussão sobre PEIs/PDIs comparece na legislação brasileira e o fato de não haver um direcionamento uniforme para a questão. Além disso, apresenta-se um levantamento das publicações acerca do tema nos últimos cinco anos. Na quarta, os documentos presentes na escola são analisados e, na quinta, os excertos dos grupos focais são trazidos para demonstrar o modo como os docentes pensam o PEI/PDI. Por fim, apresentam-se as considerações finais em torno da temática.

4 Estudantes público-alvo da educação especial são entendidos, de acordo com a Lei de Diretrizes e Bases da Educação Nacional como aqueles que têm deficiência, transtorno global de desenvolvimento e altas habilidades/superdotação (BRASIL, 1996). De acordo com a Lei Brasileira de Inclusão (Lei 13.146/2013), “[...] considera-se pessoa com deficiência aquela que tem impedimento de longo prazo de natureza física, mental, intelectual ou sensorial, o qual, em interação com uma ou mais barreiras, pode obstruir sua participação plena e efetiva na sociedade em igualdade de condições com as demais pessoas". 


\section{Metodologia}

A temática aqui abordada foi analisada por meio de três percursos metodológicos. O primeiro trata da pesquisa bibliográfica, com o fim de tomar conhecimento das produções sobre PEI/PDI publicadas em periódicos nacionais. A pesquisa bibliográfica consiste num “[...] apanhado geral sobre os principais trabalhos já realizados, revestidos de importância, por serem capazes de fornecer dados atuais e relevantes relacionados com o tema" (LAKATOS; MARCONI, 2001, p. 157).

Para mostrar como está se desenvolvendo o processo de construção dos PEIs/PDIs no Centro Pedagógico, no estudo aqui apresentado, foram utilizadas outras duas metodologias: pesquisa documental e grupos focais. A princípio, foi realizada uma análise de diferentes documentos existentes na escola. Oliveira (2007, p. 69) afirma que a pesquisa documental se caracteriza "[...] pela busca de informações em documentos que não receberam nenhum tratamento científico, como relatórios, reportagens de jornais, revistas, cartas, filmes, gravações, fotografias, entre outras matérias de divulgação". De acordo com Lüdke e André (1986, p. 38), são considerados documentos “[...] quaisquer materiais escritos que possam ser usados como fonte de informações sobre o comportamento humano". Para esta pesquisa, foram utilizados tanto documentos oficiais da escola (excertos do Projeto Político Pedagógico e atas de reuniões) como outros textos (relatos de reuniões, e-mails e os próprios Planos de Ensino Individualizados de Estudantes), produzidos entre 2014 e 2021.

Como a escola é um espaço no qual inúmeros documentos são arquivados e produzidos, ela se torna uma importante instância para a realização de pesquisas que utilizam como metodologia a análise documental. A escola não pode, também, deixar de produzir memória e bons registros no processo inclusivo, pois, conforme Meirelles e Maselli (2017, p. 130), “[...] a inclusão é um processo histórico e cultural que precisa de memória, e assim requer um trabalho muito atento de documentação". Dessa forma, pesquisas que têm como foco a inclusão podem se utilizar dos materiais produzidos no processo inclusivo para realizar suas análises.

A terceira estratégia metodológica adotada, nesta análise, consistiu na realização de grupos focais ${ }^{5}$ com os docentes que atuavam na escola no ano de 2019. Os grupos focais caracterizam-se como um tipo de entrevista realizada em grupo (GIL, 2002). De modo geral, as entrevistas são um tipo de interação social em que o mediador apresenta questões a serem respondidas pelos entrevistados. Nos grupos focais, além do mediador, questões podem ser propostas também pelas outras pessoas que estão participando, o que torna a interação mais rica e levanta discussões mais aprofundadas. Nesse sentido, os grupos focais são considerados mais eficazes que outras metodologias, pois cruzam diferentes pontos de vista e geram pensamentos e discussões que em uma entrevista ou questionário, por exemplo, não seriam possíveis (GATTI, 2005).

No ano de 2019, a escola contava com uma equipe de 64 professores(as) e os grupos focais tinham o objetivo de atingir pelo menos $20 \%$ da equipe. Em sua fase inicial, foi feito um convite a todos os docentes da escola para participação nos grupos focais e definidos dias e horários diferentes para atingir um público maior. Foram realizados cinco grupos focais, que atingiram $40 \%$ do corpo docente da escola. O número de participantes variou de três a sete, além dos moderadores e da bolsista de iniciação científica. Em todos os encontros, foi feita uma breve caracterização do estudo e cada professor contou sua experiência com inclusão, os desafios vivenciados e as aprendizagens construídas. Após a coleta de dados, os grupos focais foram transcritos e enviados

\footnotetext{
5 Os grupos focais foram realizados no contexto da pesquisa Inclusão na Escola Regular de Tempo Integral: principais desafios para o cotidiano escolar e para a formação docente. A referida pesquisa foi submetida ao Comitê de Ética em Pesquisa e aprovada em vinte de outubro de 2017, número do Projeto: CAAE 76795417.0.0000.5149. O objetivo dos grupos focais foi discutir as experiências e concepções acerca da inclusão de estudantes PAEE no CP. Foram realizados seis grupos focais com docentes do Centro Pedagógico, buscando compreender de que forma eles têm percebido a inclusão no $\mathrm{CP}$, as vivências que já tiveram em torno desse tema e as demandas que percebem na instituição.
} 
a cada um dos professores participantes que revisaram e aprovaram o texto. No caso específico deste estudo, serão usados excertos que discutiam questões relativas às adaptações curriculares e aos Planos de Ensino Individualizados.

\section{Os Planos de Ensino Individualizados na Legislação Brasileira e em trabalhos acadêmicos}

A discussão sobre Planos de Ensino Individualizados no Brasil não está estabelecida de forma explícita na legislação educacional. Diferente de países como Portugal ${ }^{6}$ e França, nos quais há uma definição clara sobre como os PEIs/PDIs devem se organizar, no Brasil, é possível verificar, por meio dos documentos e das legislações relacionados à educação, que não há dispositivos legais que normatizam o planejamento individualizado para o ensino de crianças e adolescentes com deficiência e/ou que apresentam demandas específicas de aprendizagem. No artigo 59 da Lei de Diretrizes e Bases da Educação Nacional (LDBEN 9394/1996) estabelece-se que "[...] os sistemas de ensino assegurarão aos educandos com deficiência, transtornos globais do desenvolvimento e altas habilidades ou superdotação: currículos, métodos, técnicas, recursos educativos e organização específicos, para atender às suas necessidades" (BRASIL, 1996). É a partir dessa prerrogativa legal que instrumentos como o PEI/PDI são pensados, ainda que não sejam diretamente mencionados na legislação.

Partindo-se da perspectiva de uma escola inclusiva, qualquer estudante que apresente alguma demanda educacional deve contar com uma adaptação ou flexibilização curricular específica no seu processo de escolarização, independentemente da existência de diagnóstico ou laudo médico que o caracterize como pertencente ao PAEE. Tannús-Valadão e Mendes (2018, p. 11) constatam "[...] a existência de dispositivos em algumas leis estaduais e municipais, particularmente do começo dos anos 2000, garantindo o plano educacional que assume nomenclaturas diversas", como Plano de Desenvolvimento Individualizado (PDI) e Plano de Atendimento Individualizado (PAI). Também são encontradas nomeações como Plano de Ensino Individualizado (PEI) (TANNÚS-VALADÃO; MENDES, 2018), Programa Educativo Individual (PEI) (PORTUGAL, 2008), Plano de Desenvolvimento Individual (PDI) (MINAS GERAIS, 2018) e outras nomenclaturas semelhantes.

Tannús-Valadão e Mendes (2018) acrescentam ainda que a Resolução n. 4, promulgada em 2009 , trata da necessidade dos sistemas de ensino assegurarem o plano de atendimento educacional especializado (AEE) ${ }^{7}$, responsabilidade do professor do AEE. Elas argumentam que a própria resolução nacional que trata desse tipo de planejamento vincula a sua execução aos serviços prestados pelos professores de AEE ou de Educação Especial, que "[...] não são necessariamente, centrados nos estudantes, não havendo, ainda, referências a como o ensino na classe comum é planejado" (TANNÚS-VALADÃO; MENDES, 2018, p. 13).

A perspectiva de um planejamento distinto apenas para o AEE é apresentada também por Poker et al. (2013, p. 12) que citam que o Plano de Desenvolvimento Individual (PDI) é um "[...] roteiro de avaliação e intervenção pedagógica para alunos que frequentam a SRM [Sala de Recursos Multifuncional]". Ele é composto por um roteiro de avaliação e por um roteiro para elaboração da intervenção pedagógica especializada, denominado Plano Pedagógico Especializado, que engloba

6 Em Portugal, a nomenclatura utilizada é Programa Educativo Individual (PEI), de acordo com o Decreto-lei n. 3, de 2008, que regulamenta como o documento deve ser elaborado.

7 De acordo com a Política Nacional de Educação Especial na Perspectiva da Educação Inclusiva (BRASIL, 2008), o AEE tem como objetivo complementar ou suplementar as ações desenvolvidas no ensino comum para educandos PAEE, ou seja, ele não tem caráter substitutivo em relação às práticas que se desenvolvem na escola comum e deve ser transversal aos diferentes níveis de ensino. 
tanto "[...] proposições para o atendimento pedagógico do aluno, considerando seu potencial de aprendizagem, [quanto] propostas de ações necessárias para atender às suas necessidades educacionais especiais no âmbito da escola, da sala de aula, da família e dos serviços de apoio" (POKER et al., 2013, p. 12). É possível perceber como há divergências entre pesquisadores do tema e a legislação educacional sobre a qual a característica central do PEI/PDI: estar centrado no atendimento educacional especializado, ter seu foco direcionado ao ensino comum ou buscar estabelecer uma relação entre ambos.

A Resolução n. 2, que institui as Diretrizes Nacionais para a Educação Especial na Educação Básica, de 2001, no art. 8, apregoa que as escolas regulares devem prover "[...] as flexibilizações e adaptações curriculares que considerem o significado prático e instrumental dos conteúdos básicos, metodologias de ensino e recursos didáticos diferenciados e processos de avaliação adequados ao desenvolvimento dos alunos [...]" com necessidades educacionais especiais (BRASIL, 2001). Em 2011, o decreto n. 7.611 cita brevemente a necessidade de assegurar adaptações razoáveis a partir das necessidades individuais. Já a Lei Brasileira de Inclusão prevê apenas, no art. 28, a elaboração de plano de atendimento educacional especializado, e sugere em outros trechos adaptações razoáveis, visando à garantia do acesso ao currículo (BRASIL, 2015).

No Estado de Minas Gerais, onde está situado o Colégio, o Conselho Estadual de Educação publicou a Resolução n. 460, em 2013, que consolida normas sobre a Educação Especial na Educação Básica, no Sistema Estadual de Ensino de Minas Gerais. A Resolução apregoa no art. $7^{\circ}$, que compete às instituições de ensino "[...] elaborar e aplicar o PDI, visando avaliar as condições e necessidades dos alunos” (MINAS GERAIS, 2013, p. 20). A Secretaria de Estado de Educação, em 2018, definiu orientações para a construção do PEI/PDI, como:

[...] um instrumento obrigatório para acompanhamento, avaliação, regulação da aprendizagem e planejamento da intervenção pedagógica visando ao pleno desenvolvimento e aprendizagem do/da estudante com deficiência, transtorno global do desenvolvimento (TGD) e altas habilidades/superdotação (MINAS GERAIS, 2018, p. 5, grifos do autor).

Apresenta também um detalhamento para a construção de cada item que deve estar presente nesse documento e explicita que as adaptações curriculares sugeridas podem, por vezes, não atender às necessidades dos estudantes, uma vez que o próprio estudante regula a construção do próprio conhecimento. Defende, também, que não se trata de excluir conteúdos, mas definir prioridades para facilitar o trajeto entre o que o estudante não sabe e o que precisa saber. Sendo assim, muitas vezes, "[...] a flexibilização deve ser muito mais metodológica do que de conteúdo" (MINAS GERAIS, 2018, p. 8).

A cartilha também cita a construção do Plano de Atendimento Educacional Especializado, que deve ser desenvolvido pelo professor de AEE, a partir do referencial da Educação Especial Inclusiva e deve ser baseado no PEI/PDI do estudante. "É importante ressaltar que o PDI e o PAEE [Plano de Atendimento Educacional Especializado] se constituem no planejamento do atendimento escolar da(s) escolas(s) envolvidas e se retroalimentam" (MINAS GERAIS, 2018, p. 48). É possível perceber que no nível estadual há orientações mais evidentes que mostram a necessidade de articulação entre os diferentes profissionais da educação envolvidos no processo do educando.

Já na esfera do município de Belo Horizonte (cidade em que o Colégio de Aplicação está localizado), o Plano Municipal de Educação, publicado em 2016, não faz referência explícita à elaboração de PEI/PDI ou outro documento que organize as adaptações curriculares necessárias para alguns estudantes. Mas o documento estabelece uma meta que prevê a universalização do acesso à educação básica e ao atendimento educacional especializado para estudante PAEE, "[...] 
preferencialmente na rede regular de ensino, com a garantia de sistema educacional inclusivo, de salas de recursos multifuncionais, classes, escolas ou serviços especializados, públicos ou conveniados" (BELO HORIZONTE, 2016, p. 7).

Destarte, cumpre ressaltar que tais planos se configuram como instrumentos fundamentais para garantir o acesso e a permanência do sujeito na escola, buscando, assim, a inclusão dos estudantes PAEE na escola regular. De acordo com Tannús-Valadão e Mendes (2018, p. 5), por meio do PEI/PDI é possível "[...] produzir documentação ou registro com a finalidade de promover e garantir, como um contrato, a aprendizagem de estudantes PAEE por meio da ação compartilhada pelas pessoas responsáveis ou que deverão trabalhar com esses estudantes". Nesse sentido, ainda que não haja clareza por parte da legislação sobre o tema, é fundamental que escolas se organizem para garantir a existência desse documento que registra o processo de inclusão dos educandos que necessitem de adaptações curriculares.

A fim de compreender mais acerca da questão, foi efetuada uma pesquisa bibliográfica que teve como objetivo mapear artigos e trabalhos sobre a temática publicados nos últimos cinco anos. Inicialmente, foi feita uma pesquisa no Google Acadêmico, usando como termos de busca "plano de ensino individualizado", "plano educacional individualizado" e "plano de desenvolvimento individualizado".

Foram encontrados 46 textos, sendo que destes 27 eram artigos, seis eram trabalhos de congresso, dez dissertações e três capítulos de livros. Também foi feita uma busca no Scielo ${ }^{8}$, em que foram encontrados quatro artigos, sendo que desses, desses já haviam aparecido na busca do Google. Para refinar ainda mais a análise, optamos por investigar dois periódicos especificamente. O primeiro deles foi a Revista Cadernos do Aplicação, para a qual este artigo está sendo submetido. Nela, não foram encontrados artigos que tratassem da temática. Além disso, o periódico Educação Especial da UFSM (que aborda especificamente questões sobre educação especial e não está indexado no Scielo) também foi analisado, sendo que foram encontrados três artigos sobre o tema no periódico. Assim, foram encontrados 46 trabalhos sobre PEI no final, como pode ser visto na tabela a seguir:

Tabela 1: Trabalhos encontrados acerca de PEI nos últimos cinco anos

\begin{tabular}{|l|c|c|c|c|c|}
\hline Site de busca & Artigos & $\begin{array}{c}\text { Trabalhos } \\
\text { congresso }\end{array}$ & Dissertação & Capítulo livro & Total \\
\hline Google Acadêmico & 20 & 6 & 10 & 3 & 39 \\
\hline Scielo & 4 & - & - & - & 4 \\
\hline Revista Cadernos do Aplicação & 0 & - & - & - & 0 \\
\hline Revista Educação Especial UFSM & 3 & - & - & - & 3 \\
\hline Total & 27 & 6 & 10 & 3 & 46 \\
\hline
\end{tabular}

Fonte: Elaborado pelas autoras.

As produções apresentam temáticas diversas e são unânimes em mostrar as potencialidades do PEI/PDI para pensar a educação de estudantes PAEE ou que apresentam demandas específicas na aprendizagem. Ao analisar diferentes níveis de ensino e por meio de variadas metodologias, é possível perceber como o PEI/PDI auxilia no processo de organização do trabalho pedagógico e na aprendizagem dos educandos. Os artigos mostram, também, como a reflexão sobre PEI/PDI revela a concepção de educação inclusiva de docentes e instituições.

8 O Scientific Electronic Library Online (SCIELO) é um portal de periódicos e revistas brasileiras que disponibiliza artigos e textos completos de revistas na Internet. 


\section{A construção de PEls/PDIs em um colégio de aplicação}

A elaboração de PEIs/PDIs para acompanhamento de estudantes no Colégio de Aplicação, estudada neste artigo, é um processo em constante desenvolvimento, a partir de discussões coletivas. O Centro Pedagógico da UFMG foi fundado em 1954, e, atualmente, oferta o ensino fundamental em tempo integral. O ingresso dos estudantes se dá por meio de sorteio público de cinquenta vagas para o primeiro ano do ensino fundamental, desde 1993. Antes disso, os estudantes ingressavam após participarem de processo seletivo, com a utilização de provas (CUNHA; ALVES, 2013). A entrada por meio de sorteio público permite o ingresso de estudantes com variadas condições de aprendizagem. Dessa forma, desde 1993, a escola conta com o ingresso de estudantes público-alvo da educação especial que ingressam pelo sorteio, o que mobilizou discussões sobre a inclusão, contudo, ainda de forma incipiente e descontínua. A partir de 2016, a escola passou a reservar 5\% de suas vagas para o PAEE.

A partir de 2017, a escola iniciou o Atendimento Educacional Diferenciado, com objetivo semelhante ao AEE, mas com características específicas. Ele recebe esse nome pois acontece no turno de aulas dos alunos, em horários específicos, de acordo com a demanda de cada estudante e da disponibilidade da professora do AED. O CP é uma escola de tempo integral, com jornada diária de sete horas, o que inviabiliza o atendimento no contraturno de escolarização, conforme sugere a legislação brasileira. $\mathrm{O}$ atendimento é oferecido, em caráter experimental, de uma forma diferenciada, em sala específica, na forma de apoio (atendimentos que favorecem o acesso ao currículo) e de complementação (trabalho pedagógico complementar necessário ao desenvolvimento de competências e habilidades próprias nos diferentes níveis de ensino). A carga horária destinada a esse atendimento varia conforme as demandas dos estudantes. $\mathrm{O}$ encaminhamento para o AED é discutido pela equipe docente que acompanha o estudante, juntamente à equipe pedagógica.

A análise dos documentos presentes na escola permitiu identificar no recorte temporal deste artigo (2014 a 2021) um movimento significativo em torno da discussão sobre PEIs/PDIs e como a concepção sobre esse documento foi sendo construída institucionalmente. Foram consultadas atas de reunião, PEIs/PDIs dos estudantes nesse período, entre outros. O Centro Pedagógico conta com uma instância deliberativa sobre as práticas educativas da escola nomeada de Coordenação Pedagógica (Coped). Analisando as atas de reuniões da citada instância, entre 2014 e 2021, é possível encontrar pelo menos uma ata por ano que faz referência ao PEI/PDI, conforme detalhado a seguir.

Em 2014, foram encontradas nove atas que citam o PEI/PDI. Duas serão destacadas na análise, em função de seu conteúdo. A primeira, datada de março, registra o estabelecimento de uma data em maio para envio dos PEIs/PDIs dos estudantes por ciclo. Na segunda, realizada ao final do ano, o grupo discutiu o caso de estudantes com "defasagem na aprendizagem", que não poderiam ser retidos, por causa da faixa etária. Foi proposta a aprovação automática, com a elaboração de PEI/PDI para esses estudantes no ano seguinte, bem como um projeto especial, para terminalidade ou continuidade. Em dezembro de 2014, o coordenador da instância enviou um layout do PEI/PDI para ser divulgado, a fim de que os trabalhos no ano seguinte fossem efetivados. 
Figura 1: Layout de PEI/PDI 2014

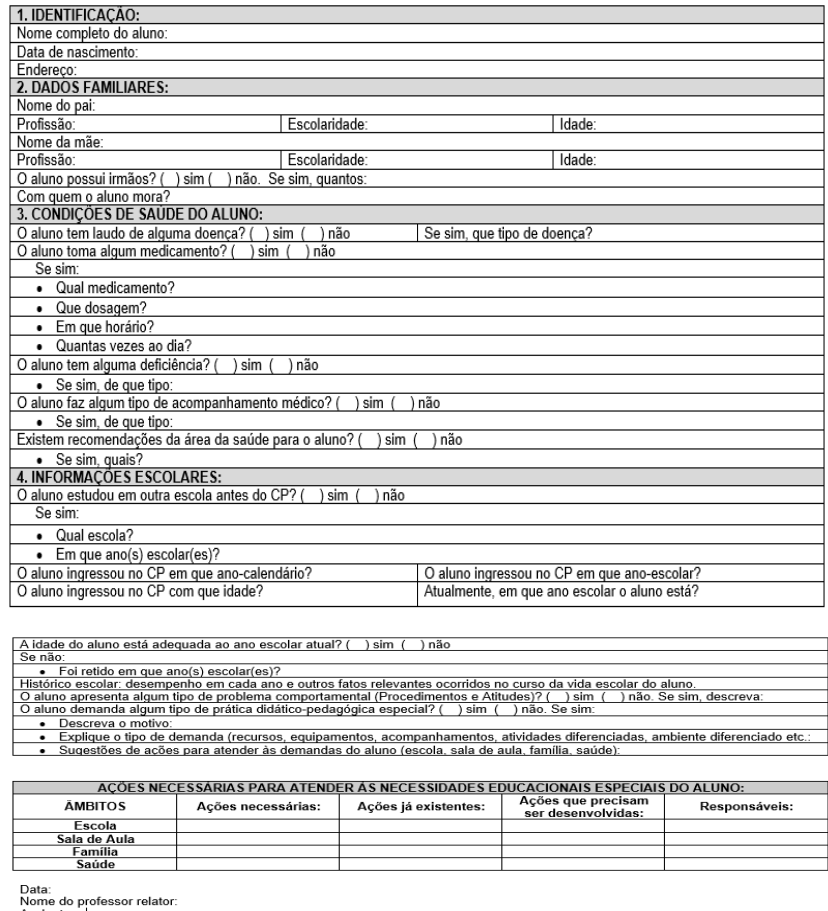

Fonte: Arquivo da escola.

Em 2015, foram encontradas nove atas citando o PEI/PDI. Há um registro da décima quinta reunião ordinária, realizada em junho, que cita o ponto de pauta para retorno sobre avaliação de "alunos de inclusão". É importante registrar que a menção feita dessa forma aparece na escola, mas vem sendo problematizada em diferentes instâncias, já que não se pode afirmar que um aluno é "de inclusão". Na perspectiva inclusiva, todos os estudantes devem estar incluídos e não apenas os que se caracterizam como público-alvo da educação especial. Segundo o que consta no registro, os professores, até então, estavam avaliando alguns estudantes PAEE com um relatório reflexivo sobre o desenvolvimento do estudante naquele ano.

Diante da dúvida se apenas esse relatório seria suficiente para a avaliação dos estudantes ou não, a instância colegiada fez uma consulta à Diretoria de Educação Especial da Secretaria Estadual de Educação de Minas Gerais e o retorno foi que os alunos deveriam receber conceito em todas as disciplinas e, no seu histórico, de acordo com a Orientação 01/2013 do MEC, a Resolução n. 460, CFE/2013, a Resolução n. 2 do CNE e o Guia de Orientação da Educação Especial na rede estadual de ensino de Minas Gerais. Segundo o último documento citado, no item 3.3 sobre a conclusão, fica estabelecido que o histórico dos estudantes PAEE segue o mesmo padrão da legislação vigente, com registro obrigatório do aproveitamento do aluno, "[...] sendo representativa do desenvolvimento do aluno em relação a si mesmo e considerando-se os objetivos da etapa de ensino em que ele está sendo avaliado, conforme o Plano de Desenvolvimento Individual (PDI)" (MINAS GERAIS, 2014, p. 13). Após esse retorno, ficou estabelecido na instância que todos os professores deveriam enviar os conceitos dos alunos PAEE de 2015 em diante.

No mesmo ano, também foram localizados onze documentos na escola com uma estrutura que se aproxima da de um PEI/PDI. Nesse momento, no Centro Pedagógico, especificamente, esses documentos eram nomeados de Plano de Desenvolvimento Individualizado (PDI). Cabe registrar que, em 2015, a escola tinha cinco estudantes PAEE regularmente matriculados. Além dos onze documentos citados, foram encontrados documentos em que se constavam o levantamento de conceitos de estudantes e relatórios de análise documental de toda a trajetória escolar 
de alguns estudantes, para subsidiar a elaboração de PEIs/PDIs. A presença de onze planos indica a percepção de que esse documento não deve ser utilizado apenas para educandos PAEE, mas para todos aqueles que tenham demandas específicas de aprendizagem. Nesse sentido, é possível afirmar uma concepção de educação inclusiva focada não na deficiência, mas no indivíduo, como apontam Tannús-Valadão e Mendes (2018).

Embora tenham sido encontrados onze registros de PEI/PDI em 2015, no ano de 2016 foram localizados apenas quatro registros sobe PEI/PDI nas atas da Coped, sendo que o registro da décima quarta reunião ordinária da Coped, realizada em agosto, cita a solicitação da elaboração do PEI/PDI de "todos os alunos de inclusão", com a delimitação de estratégias e atividades a serem desenvolvidas com os alunos. Na reunião, houve uma discussão sobre qual seria o público do PEI/ PDI. Ele se limitaria aos estudantes PAEE ou seria para todos os alunos com outros transtornos e dificuldades de aprendizagem? O grupo encaminhou que a prioridade deveria ser dos estudantes PAEE e que os docentes analisassem cada um dos outros casos para avaliar a necessidade ou não do PEI/PDI. Nos registros pesquisados, não foram encontrados PEIs/PDIs dos estudantes. Tal fato evidencia como o movimento de produção desse documento na instituição não é linear e, em alguns momentos, é possível perceber certa paralisação das discussões.

No ano de 2017, foram realizadas 21 reuniões da Coped e em doze delas discutiu-se sobre o PEI/PDI. A primeira reunião extraordinária da Coped, realizada em fevereiro, apresenta como ponto de pauta a organização dos PEIs/PDIs, estabelecimento de prazos e de responsáveis e levantamento de prioridades. O registro da reunião cita que, diante do número de alunos PAEE, seria necessário desenvolver um PEI/PDI para cada aluno, visando, inclusive, à avaliação dos alunos. Ficou estabelecido ainda que estudantes retidos deveriam ser tratados com prioridade na elaboração dos PEIs/PDIs e que cada aluno contaria com um professor referência na construção do documento. É possível perceber aqui que o $\mathrm{PEI} / \mathrm{PDI}$ era pensado para dois públicos principais: estudantes PAEE e estudantes retidos. Na perspectiva de Hudson e Borges (2020, p. 4-5), o "[...] PDI é um recurso que deve ser utilizado de forma obrigatória. Desse modo, todos os alunos PAEE matriculados nas escolas da rede estadual mineira devem possuir um Plano". Já para Tannús-Valadão (2018), o PEI/ PDI deve ser elaborado apenas nos casos em que o aluno estiver em desvantagem ou defasagem do currículo padrão. O que se percebe é que dentro da própria literatura consultada há divergências quanto à obrigatoriedade ou não da elaboração dos PEIs/PDIs, refletindo nas organizações das instituições escolares, algo que também ocorre na escola em que a investigação foi realizada.

Em 2017, também houve a oferta de um curso de capacitação em PEI/PDI com dois encontros para capacitação geral e treinamento prático para a elaboração de PEI/PDI, para todos os servidores da escola que manifestaram interesse. Importante observar que este é o segundo ano da reserva de vagas para estudantes PAEE na escola, o que parece mobilizar a discussão sobre PEIs/PDIs tanto nas instâncias colegiadas como em movimentos de formação continuada. Já a décima reunião ordinária, de maio, estabeleceu que os $\operatorname{ciclos}^{9}$ deveriam entregar os PEIs/PDIs dos alunos com deficiências.

No mesmo ano, foram encontrados PEIs/PDIs de treze estudantes, sendo que dez deles eram para estudantes PAEE e os outros três apresentavam outras demandas como dislexia ou dificuldades de aprendizagem. Os documentos seguem padrões de apresentação e formatação diferentes entre si, sendo que quatro deles se apresentavam como um relatório intitulado Ações pedagógicas desenvolvidas para/com os estudantes com necessidades educacionais especiais, com divisões por componentes curriculares e descrição de metas, estratégias e formas de avaliação para

9 O Centro Pedagógico adota três ciclos de formação humana, com três anos de duração cada um. Os ciclos são entendidos no CP como Ciclos de Formação Humana, em que o tempo escolar toma uma dimensão pedagógica diferenciada, proporcionando a flexibilização e a aproximação do aprendizado à realidade da turma e do aluno, superando a estrutura seriada e anual que condicionava a aprendizagem a uma grade com tempos rígidos e preestabelecidos. Isso flexibilizou os tempos escolares, e baseou-se na idade cronológica dos estudantes e no tempo de aprendizagem. 
os estudantes. Outra observação interessante é que a maioria dos PEIs/PDIs enviados após maio, data da décima reunião ordinária, apresentam um formato semelhante com objetivos e recursos separados por disciplina, como um compilado, conforme deliberações da instância colegiada. A figura 2, a seguir, mostra a estrutura desses diferentes documentos.
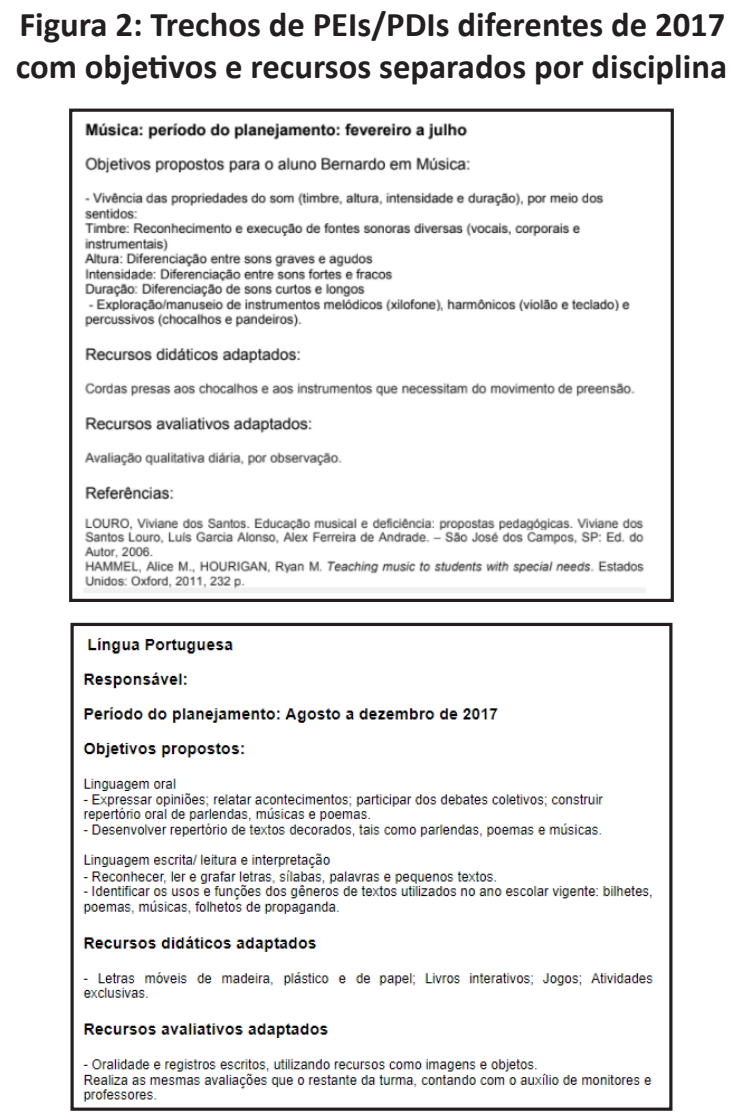

Fonte: Arquivos da escola.

Em 2018, houve um novo movimento na escola de discussão sobre a prática inclusiva. Isso se reflete também nos registros documentais: foram realizadas dezesseis reuniões da instância, e em 1/4 delas, ou seja, quatro reuniões, o PEI/PDI foi ponto de pauta da discussão coletiva. No mês de março, todos os servidores da escola receberam convite por e-mail para participar do Projeto Laboratório de Currículo Inclusivo. Tratava-se de um projeto de ensino, pesquisa e extensão, fruto de uma parceria entre o CP e o LAPPEI - FaE/UFMG -, com a proposta de reuniões quinzenais com um grupo de interessados em discutir temas relacionados à inclusão e aos estudos de caso de estudantes do CP. Várias reuniões do grupo tiveram como pauta única a elaboração de PEIs/PDIs, com análise coletiva de modelos e exemplos de escolas públicas e privadas. O projeto se concretizou durante todo o ano de 2018, com reuniões de março a dezembro.

Na quarta reunião ordinária, realizada no mesmo mês, registrou-se que o Setor Multiprofissiona ${ }^{10}$ da escola juntamente com o Núcleo de Acessibilidade e Inclusão da UFMG haviam proposto um modelo de PEI/PDI, buscando articular todas as informações necessárias, após verificar que os PEIs/PDIs produzidos pela escola apresentavam informações e formatos diferentes. Contudo, na reunião realizada pelo Laboratório de Currículo Inclusivo, definiu-se que o modelo de PEI/PDI

10 O Setor Multiprofissional se organiza em dois Serviços: Apoio Psicossocial (responsável pelo acolhimento e acompanhamento do desenvolvimento do estudante, nos aspectos emocional, psicológico e social, orientando-o nos processos de integração e inclusão social na unidade escolar e na escolha profissional) e Pedagógico (responsável pelo acompanhamento do desenvolvimento do estudante, no aspecto pedagógico, e pelo acompanhamento dos processos de avaliação da aprendizagem dos alunos). O Setor conta com pedagogos, psicólogo e assistente social. 
da escola deveria ser mais completo, com o acréscimo de mais informações do que o que havia sido anteriormente proposto. Um dos membros presentes na reunião da instância solicitou que o modelo do documento fosse mais prático, com diretrizes para os professores, e também com informações do planejamento das aulas para esses alunos.

Essa solicitação confirma a percepção de $40 \%$ dos respondentes de uma pesquisa qualitativa realizada com 1286 profissionais da educação de Minas Gerais sobre esse instrumento, que concordam que o PEI/PDI precisa ser melhor elaborado, para facilitar seu preenchimento e utilização (HUDSON; BORGES, 2020). Nessa direção, as autoras Hudson e Borges (2020, p. 9) mostram que "[...] houve o indicativo de que o Plano precisa ser aprimorado, pois é demorado de se preencher e, muitas vezes, os docentes não têm disponibilidade de tempo para um trabalho de preenchimento em equipe". Apesar desse retorno, metade dos pesquisados concordam que o instrumento é excelente para favorecer o processo inclusivo de estudantes. As autoras recomendam ainda o investimento em capacitação da equipe de professores para um uso mais efetivo do PEI/PDI.

Em maio, na quinta reunião ordinária, cita-se que a discussão sobre o modelo de PEI/PDI da escola havia sido paralisada na instância, para que essa discussão fosse feita de forma ampliada na escola, articulada à discussão geral sobre inclusão que estava sendo feita por ocasião da reformulação do PPP. Diante do fato, foi proposto um modelo transitório até a finalização da discussão, de forma mais simplificada quando comparado aos modelos anteriores, que pode ser visto na figura 3 .

\section{Figura 3: Modelo de PEI/PDI 2018}

\section{Plano de Desenvolvimento/Ensino Individual}

Periodo: $X X X X X$ a $X X X X X$ de 2018

Responsável: $X X X, X x X$ e $X X X$

Estudante: $x x x$

Turma: $\mathbf{X}$

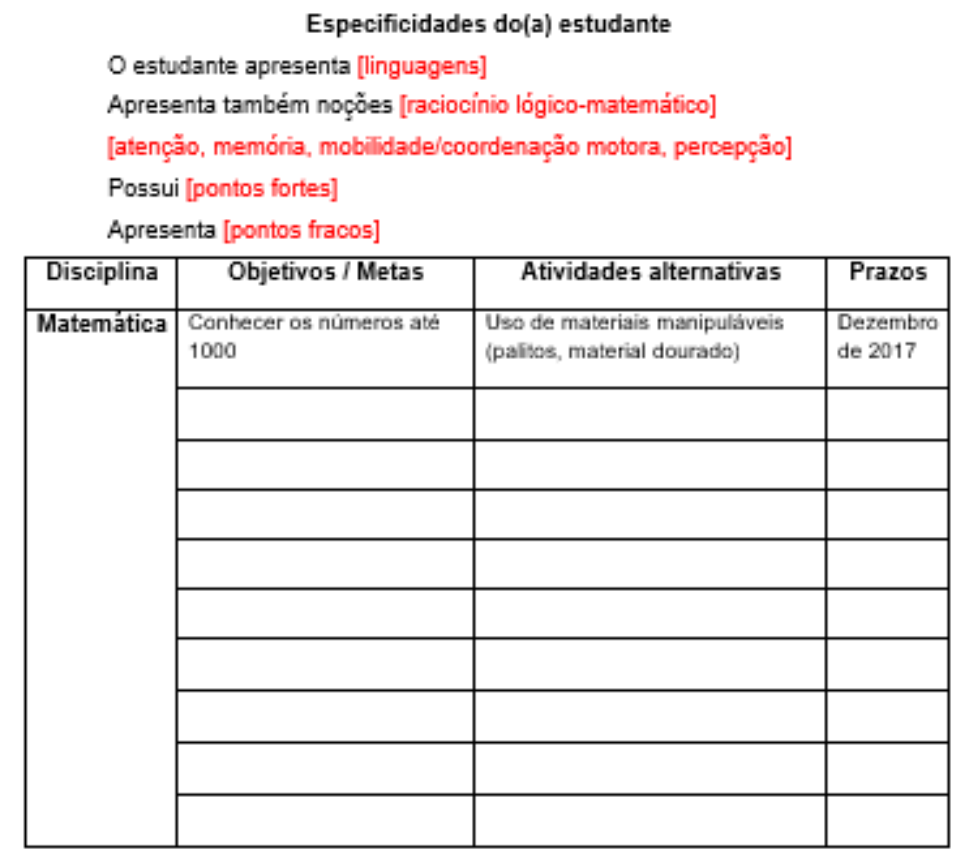

Fonte: Arquivo da escola.

$\mathrm{Na}$ análise dos documentos de 2018, foram encontrados treze documentos que se assemelham a PEI/PDI de estudantes, sendo que nove eram estudantes PAEE, três eram estudantes com dislexia ou dificuldades de aprendizagem e um estudante apresentava problemas comportamentais, com registros de agressividade. O PDI desse estudante apresentava propostas de intervenção para 
auxiliar o aluno nessas questões. Destaca-se, ainda, que, em apresentação de pôster sobre o Atendimento Educacional Diferenciado (AED) no CP, no $8^{\circ}$ Congresso Brasileiro de Educação Especial, realizado na Universidade Federal de São Carlos, em novembro de 2018, o avaliador sugeriu que a escola passasse a utilizar a sigla PEI, visto que PDI se confunde com outro documento das instituições federais com a mesma sigla (Plano de Desenvolvimento Institucional). A partir de então, a escola passou a adotar a sigla $\mathrm{PEI}^{11}$.

No ano de 2019, foram realizadas dezesseis reuniões da instância, e em duas atas constam registros de discussões sobre o PEI. Na primeira ata, da décima quarta reunião ordinária, realizada em novembro, o ponto de pauta tratava da definição da escola sobre a elaboração do PEI apenas para estudantes que demandam adaptação curricular ou para todos os estudantes PAEE. Na reunião seguinte (décima quinta reunião ordinária), realizada em dezembro, foi estabelecido que o "[...] PEI seja apenas para estudantes que necessitem de adaptação curricular e que, para aqueles que não a necessitem, seja escrito um relatório (em que se afirma a ausência de necessidade de PEI), além do registro mais detalhado na ficha global" (CENTRO PEDAGOGICO, 2019, p. 3). Foram analisados quatro PEIs elaborados em 2019 para quattro estudantes PAEE. O modelo era semelhante ao adotado no ano anterior. Além disso, foram elaborados vários relatórios para outros estudantes PAEE que não demandavam PEI.

Em 2020, foram realizadas quatorze reuniões pela instância e em duas atas constaram discussões acerca da elaboração dos PEIs dos estudantes do Centro Pedagógico. A primeira ata é da terceira reunião ordinária, realizada em junho, e trata da atualização dos PEIs dos estudantes PAEE, para o contexto do ensino remoto, iniciado em agosto de 2020, devido à pandemia decorrente do coronavírus. A segunda ata, referente à oitava reunião ordinária, realizada em setembro, apresenta uma discussão ampla sobre a situação dos PEIs no contexto do ensino remoto, avaliando a situação em cada ano escolar. Ao final do período, foram enviados para a instância colegiada três registros de PEIs para três estudantes PAEE. Ressalta-se que, com a pandemia e com o início do ensino remoto emergencial ${ }^{12}$, houve um período de adaptação e organização das atividades, tanto por parte dos docentes quanto por parte dos professores. Algumas famílias de estudantes PAEE tiveram muita dificuldade em propiciar a participação dos estudantes PAEE nas atividades, de forma a contribuir para o estabelecimento de PEIs com metas específicas para esse período.

No ano de 2021, em oito reuniões realizadas pela instância (até maio), foram localizados três registros de reunião sobre o PEI. O primeiro é da terceira reunião ordinária, realizada em fevereiro, e estabelece uma data limite para envio dos PEIs construídos no ano letivo de 2020, para arquivamento nos registros da instância. A segunda ata é da quarta reunião ordinária do ano, realizada em março, e sugere uma data limite para elaboração dos PEIs para os estudantes no ano vigente, "[,...] entendendo que esses PEIs são necessários tanto para a avaliação de estudantes PAEE na $1^{\mathrm{a}}$ etapa bem como para o atendimento da coordenação pedagógica e dos profissionais do Multi às famílias de tais estudantes" (CENTRO PEDAGÓGICO, 2021, p. 10). A terceira ata, de abril de 2021, apenas reforça a data estabelecida para envio dos PEIs à instância colegiada. Ressalta-se que o modelo que segue sendo adotado pela escola é o da figura 3 e que com dois meses do início das aulas, os professores se organizaram e dois estudantes PAEE já contam com PEIs atualizados e apresentados em reunião com as famílias dos estudantes. Atualmente, o CP conta com 29 estudantes PAEE. Em síntese, a documentação a respeito de PEIs na escola é a que se apresenta na tabela 2, a seguir:

11 Por esse motivo, daqui em diante, utilizaremos apenas a sigla PEI, já que essa passa a ser a nomenclatura adotada pela escola. 12 Conforme Portaria no 1819 da Reitoria da UFMG de dezoito de março de 2020, foi determinada a suspensão das aulas presenciais da UFMG. Entre março e agosto, foram criadas as diretrizes para o início do ensino remoto emergencial, iniciado em agosto de 2020 , pela escola. 
Tabela 2: PEI Centro Pedagógico

\begin{tabular}{|l|c|c|c|c|c|c|}
\hline Ano & Reuniões Coped & Citação Reuniões & PDI/PEI & PEI PAEE & PEI outros & Alunos PAEE \\
\hline $\mathbf{2 0 1 4}$ & 33 & 9 & 0 & 0 & 0 & 4 \\
\hline $\mathbf{2 0 1 5}$ & 25 & 9 & 11 & 2 & 9 & 5 \\
\hline $\mathbf{2 0 1 6}$ & 22 & 4 & 0 & 0 & 0 & 9 \\
\hline $\mathbf{2 0 1 7}$ & 21 & 12 & 13 & 10 & 3 & 11 \\
\hline $\mathbf{2 0 1 8}$ & 16 & 4 & 13 & 9 & 4 & 15 \\
\hline $\mathbf{2 0 1 9}$ & 16 & 2 & 4 & 4 & 0 & 19 \\
\hline $\mathbf{2 0 2 0}$ & 14 & 2 & 3 & 3 & 0 & 26 \\
\hline $\mathbf{2 0 2 1}$ & 8 & 3 & 2 & 2 & 0 & 29 \\
\hline
\end{tabular}

Fonte: Elaborado pelas autoras.

A análise documental evidenciou os esforços envidados para garantir a adequação curricular a qual os estudantes com deficiências (ou não) têm direito. É possível perceber que esse processo não foi linear, tampouco está finalizado. As reflexões realizadas coletivamente, bem como os diferentes modelos de PEI produzidos mostram uma escola em movimento para pensar nas estratégias educativas mais adequadas. $\mathrm{O}$ volume significativo de documentos produzidos e seu arquivamento na escola evidenciam uma preocupação não apenas com a produção dos documentos, mas também com a produção de conhecimento acerca da temática. Nesse sentido, após a análise dos documentos, foi importante compreender um pouco mais das percepções dos sujeitos envolvidos nesse processo. Assim, analisar as falas dos professores emergiu como uma importante ferramenta metodológica, como evidenciado no próximo tópico.

\section{O PEI nas falas dos docentes}

As discussões sobre PEI emergiram nas falas dos docentes em três dos cinco grupos focais realizados em 2019. É importante registrar que não havia perguntas específicas voltadas para esse assunto no roteiro dos grupos, mas, à medida que os professores foram relatando suas experiências, o processo de construção desse documento foi tematizado. De modo geral, as falas sobre PEI articulavam-se em dois eixos. O primeiro se refere à percepção da necessidade de fazer esse documento a partir do momento em que se entendem as especificidades do educando. O segundo se relaciona à necessidade de trabalho coletivo para elaborar um PEI. Com relação ao primeiro eixo, a Professora A afirma que:

\footnotetext{
Mas esse projeto, para ele ser bacana e inclusivo, olha, é no conhecer aquele outro, nas questões que ele traz. Mesmo que tenha um laudo, mesmo que seja, por exemplo: "tal síndrome, tem determinadas características", mas aquela criança é uma criança com uma história com questões que ela vai trazer pra gente, com a interação com aquela turma, porque depende muito como que aquela turma vai estar... todas essas questões vão influenciar pra gente traçar e criar para ele esse - vamos dizer aqui - PDI, esse projeto, esse caminho esse percurso aí do ensino fundamental dele (Professora A, Grupo Focal 1).
}

A fala da professora coaduna com a ideia defendida neste artigo de que o PEI deve ser pensado a partir das especificidades do educando. Como apontam Silva et al. (2020, p. 136) “[...] é necessário atender às necessidades específicas de todos os alunos, ultrapassando as barreiras que os impedem de aprender". Dessa forma, mais importante do que o diagnóstico, são as especificidades 
e demandas que aquele sujeito singular apresenta para a escola. Esse entendimento é fruto de um processo de contato com esses estudantes e leva ao questionamento das próprias concepções que se tem acerca do que seja a inclusão, como mostra o excerto da fala a seguir:

A minha linha era de trabalhar com ele e com a turma sempre com as mesmas coisas, mas adaptando. E aí, assim, é um momento muito importante porque foi a hora que eu comecei a questionar né [...] porque na época eu trabalhava com matemática e ele não conseguia fazer associação um a um, por exemplo, correspondência um a um... Então, coloca lá 7 copinhos, pega 5 pra mim... Ele não conseguia fazer um, dois, três. E as outras crianças, eu já estava no primeiro semestre chegando no 100. E aí esse foi o primeiro impacto assim de questionar, porque até então eu era defensora árdua do "é a mesma coisa para todo mundo com algumas adaptações necessárias”. É preciso fazer uma adaptação curricular da educação infantil com habilidades lá da educação infantil para essa criança (Professora P, Grupo Focal 2).

A concepção de que inclusão é ensinar a mesma coisa para todas as crianças é questionada pela professora à medida que ela entra em contato com um estudante que demandava não apenas adaptações metodológicas, mas também curriculares. Assim, a necessidade de adaptar as metas curriculares e pensar a inclusão a partir de cada indivíduo emerge, produzindo uma mudança no olhar. Nesse sentido, caminha-se para uma concepção educacional que considera que "[...] cada estudante é um estudante, e não mais o estudante” (LIMA; MANTOAN, 2017, p. 831).

É preciso registrar, todavia, que para que essa concepção se efetive na escola não basta o trabalho de um docente. É necessário que toda a equipe esteja envolvida a fim de que se construa um projeto educativo inclusivo, como evidenciam os trechos agrupados no segundo eixo de análise. Essa ideia aparece na fala da Professora L, quando afirma que:

Eu sentia nesses primeiros momentos com o J., o R. e o V. é que a gente tinha uma movimentação, pelo menos no segundo ciclo, de poucos professores, e esses poucos professores precisavam encampar o negócio e tinha uma demanda que vinha, superior, é preciso escrever um PDI, é isso ficava no mesmo professor que era orientador do monitor e só ele tinha que fazer tudo e esse professor, então acabava sendo um caso de inclusão daquele professor e não de uma turma, de um ciclo. (Professora L, Grupo Focal 3).

O trabalho colaborativo é fundamental no processo de construção do PEI, pois ele representa as metas e as estratégias a serem adotadas com aquele estudante, a partir de reflexões feitas por diferentes instâncias que atuam com ele. Assim, quando a professora aponta a fragilidade de um trabalho desenvolvido apenas por alguns docentes, ela mostra que ainda é necessário avançar como escola na construção desse trabalho colaborativo. Hudson e Borges (2020, p. 13) afirmam que "[...] é importante que a construção do PEI seja de forma conjunta, envolvendo a participação de toda a equipe escolar". Nesse sentido, a construção do PEI deve envolver toda a equipe. Nas falas dos docentes que participaram dos grupos focais, é possível perceber avanços nessa direção:

Agora o que eu tô vendo com a chegada do V. não! A gente tem que sentar, o pessoal do terceiro ciclo como um grupo todo e traçar metas juntos para formar o plano de ensino, né [...] é difícil juntar todo mundo, mas eu acho que aos poucos os professores estão entendendo essa necessidade que sim a gente tem que, como um grupo, embarcar nessa caminhada. (Professora R, Grupo Focal 3).

Considerando o aumento gradativo de estudantes PAEE na escola após a reserva de vagas, é possível perceber que, à medida que novos estudantes chegam e outros estudantes avançam para as séries seguintes, o corpo docente passa a se interessar mais pelas temáticas da inclusão e 
buscam formas de capacitação e qualificação para promover a inclusão na escola. Nesse sentido, há indícios de que a escola caminha para a construção de um trabalho mais colaborativo no que se refere à produção das adaptações curriculares necessárias para esses educandos.

\section{Considerações finais}

Este artigo buscou analisar o que determina a legislação nacional sobre PEIs, o que parte da produção bibliográfica sobre a temática tem problematizado e o processo de construção desse documento em um colégio de aplicação. É possível perceber que a falta de uma instrução normativa nacional promove autonomia para que cada instituição defina o modo como vai conduzir o processo de construção dos PEIs internamente. Sabe-se que outros países apresentam decretos e normativas específicas que regulamentam a elaboração dos PEIs. Contudo, o tamanho, a diversidade e a proporção continental do Brasil impossibilitam o engessamento de práticas educativas, permitindo que elas sejam flexibilizadas e que caminhos mais voltados à cada realidade sejam seguidos.

Com relação aos dados apresentados, é possível verificar que a trajetória da construção dos PEIs no CP não se dá de forma contínua e linear. É possível identificar momentos de avanços e pausas, para reavaliação da prática coletiva, de forma colaborativa e em equipe, dando voz aos docentes que participam ativamente desse processo. Num primeiro momento, nos anos iniciais de análise, percebe-se um tom mais impositivo nas solicitações de PEIs dos estudantes e uma falta de clareza quanto ao propósito deste documento. Já nos anos finais de análise, percebe-se um movimento mais democrático, de discussão e tomada de decisão após realização de oficinas, cursos e reuniões realizadas sobre a temática, o que permite maior aprofundamento no assunto e mais segurança nesse processo. Outro fato importante é que o processo de construção dos PEIs acompanhou o momento histórico da escola, do ingresso de maior número de estudantes público-alvo da educação especial, após a reserva de vagas para esse público.

As falas dos docentes também indicam esse movimento contínuo e a progressiva construção de um trabalho mais colaborativo entre a equipe docente. É possível notar que o PEI, além de registrar as metas específicas, também diz acerca das concepções sobre educação inclusiva e dos movimentos realizados a fim de construir uma prática pedagógica que abarque a diferença. Nesse sentido, entendemos que a discussão a respeito dos PEIs deve ser constante. Assim como as metas para cada estudante devem ser regularmente revisitadas, é necessário discutir constantemente nas instituições de ensino os entendimentos que se tem acerca desse documento a fim de que ele não perca suas potencialidades como instrumento fundamental no processo inclusivo.

\section{Referências}

BELO HORIZONTE. Prefeitura Municipal de Belo Horizonte. Lei no 10.917, de 14 de março de 2016. Aprova o Plano Municipal de Educação de Belo Horizonte e dá outras providências. Belo Horizonte, 2016. Disponível em: https:// prefeitura.pbh.gov.br/sites/default/files/estrutura-de-governo/educacao/Plano\%20Municipal\%20de\%20Educa\%C3\%A7\%C3\%A3o\%20(2).pdf. Acesso em: 02 maio 2021.

BRASIL. Lei no 9.394, de 20 de dezembro de 1996. Brasílias, DF, 23 dez. 1996. Disponível em http://www.planalto.gov. br/ccivil_03/LEIS/L9394.htm. Acesso em: 05 maio 2021. 
BRASIL. Resolução nº 2, de 11 de setembro de 2001. Brasília, DF, 2001. Disponível em: http://portal.mec.gov.br/arquivos/ pdf/resolucao2.pdf. Acesso em: 02 maio 2021.

BRASIL. Decreto n. 7.611, de 17 de novembro de 2011. Brasília, DF, 2011.

BRASIL. Lei n. 13.146, de 6 de julho de 2015. Institui a Lei Brasileira de Inclusão da Pessoa com Deficiência (Estatuto da Pessoa com Deficiência). Disponível em: http://www.planalto.gov.br/ccivil_03/_ato2015-2018/2015/lei/l13146.htm. Acesso em: 02 maio 2021.

CALDEIRA, Maria Carolina da Silva; OLIVEIRA, Elânia de; ARAÚJO, Camila Camilozzi Alves Costa de Albuquerque. Pensar a educação inclusiva no contexto da pesquisa na educação básica: reflexões sobre as ações implementadas pelo Centro Pedagógico da UFMG. Cadernos de Aplicação, Porto Alegre, v. 33, p. 1-12, 2020.

CENTRO PEDAGÓGICO. Coordenação Pedagógica. Ata da décima quinta reunião ordinária de dois mil e dezenove, da Coordenação Pedagógica do Centro Pedagógico da Escola de Educação Básica e Profissional da UFMG. Belo Horizonte: UFMG, 2019.

CENTRO PEDAGÓGICO. Coordenação Pedagógica. Atas das reuniões da Coordenação Pedagógica do Centro Pedagógico da Escola de Educação Básica e Profissional da UFMG. Belo Horizonte: UFMG, 2021.

CUNHA, Maria Amália de Almeida; ALVES, Maria Teresa Gonzaga. “A Sorte Sorriu para Mim”: o ensino fundamental em uma escola pública diferenciada. In: REUNIÃO NACIONAL DA ANPED, 36., 2013, Goiânia. Anais [...]. Goiânia: ANPEd, 2013.

GATTI, Bernardete Angelina. Grupo focal na pesquisa em Ciências sociais e humanas. Brasília, DF: Líber Livro, 2005.

GIL, Antônio Carlos. Como elaborar projetos de pesquisa. 4. ed. São Paulo: Atlas, 2002.

HUDSON, Bruna Cristina da Silva; BORGES, Adriana Araújo Pereira. A utilização do Plano de Desenvolvimento Individual por professores de Minas Gerais. Revista Educação Especial, Santa Maria, RS, v. 33, 2020.

LAKATOS, Eva Maria; MARCONI, Marina de Andrade. Fundamentos de metodologia científica. 4. ed. São Paulo: Atlas, 2001.

LIMA, Norma Silva Trindade de; MANTOAN, Maria Teresa Egler. Notas sobre inclusão, escola e diferença. ETD - Educação Temática Digital, Campinas, v. 19, n. 4, p. 824-832, 2017.

LÜDKE, Menga; ANDRÉ, Marli. Pesquisa em educação: abordagens qualitativas. São Paulo: EPU, 1986.

MEIRELLES, Melina Chassot Benincasa; MASELLI, Marina. O papel da documentação na educação: entre palavras e ações. In: VASQUES, Carla; MOSCHEN, Simone (org.). Psicanálise, educação especial e formação de professores: construções em rasuras. Porto Alegre: Editora UFRGS, p. 119-134, 2017. [Cap. 7].

MINAS GERAIS. Conselho Estadual de Educação. Resolução n. 460, de 12 de dezembro de 2013. Consolida normas sobre a Educação Especial na Educação Básica, no Sistema. Diário Oficial de Minas Gerais, Belo Horizonte, 2013. Belo Horizonte, 2014. Disponível em: https://srefabricianodivep.files.wordpress.com/2019/02/guia-da-educac3a7c3a3o-especial-mg-versc3a3o3-atualizada.pdf. Acesso em: 06 maio 2021.

MINAS GERAIS. Secretaria Estadual de Educação. Plano de Desenvolvimento Individual do Estudante: orientações para construção. Belo Horizonte: SEE/MG, 2018.

OLIVEIRA, Djalma de Pinho Rebouças de. Planejamento estratégico: conceitos, metodologia e práticas. 23. ed. São Paulo: Atlas, 2007.

POKER, Rosimar et al. Plano de desenvolvimento individual para o atendimento educacional especializado. São Paulo: Cultura Acadêmica. Marília: Oficina Universitária, 2013.

PORTUGAL. Ministério da Educação. Decreto-lei n. 3, de 2008. Diário da República, Lisboa, 1a série, n. 4, 7 de janeiro de 2008.

POWEL, Richard; SINGLE, Helen. Focus Groups. International Journal for Quality in Health Care, v. 8, p. 499-504, 1996.

TANNÚS-VALADÃO, Gabriela; MENDES, Enicéia. Inclusão escolar e o planejamento educacional individualizado: estudo comparativo sobre práticas de planejamento em diferentes países. Revista Brasileira de Educação, v. 23, e230076, 2018. 
A construção de Planos de Ensino Individualizados (PEIs)...

TANNÚS-VALADÃO, Gabriela. Planejamento Educacional Individualizado - protocolo. São Carlos, 2017. [Palestra]

TANNÚS-VALADÃO, Gabriela. Plano Educacional Individualizado: estratégia de colaboração, tipos de avaliação e protocolo. Minicurso Plano de Ensino Individualizado ministrado no $8^{\circ}$ Congresso Brasileiro de Educação Especial. São Carlos, 2018. 133 slides.

Data de submissão: 14/05/2021

Data de aceite: 02/07/2021 